\title{
Discharge pathways and relapse following treatment from early intervention in psychosis services
}

\author{
Stephen Puntis, Jason Oke and Belinda Lennox
}

\section{Background}

Early intervention in psychosis (EIP) services are the dominant service model in the treatment of first-episode psychosis. They are a time-limited intervention and little is known about discharge destinations and outcomes once EIP treatment has concluded.

\section{Aims}

To understand discharge pathways and predictors of relapse in an EIP service.

\section{Method}

We collected data on all patients with an electronic health record treated by EIP services in Oxford Health NHS Foundation Trust in the UK between 12 January 2006 and 7 March $2017(n=701)$. Our primary outcomes were discharge destination at end of treatment and relapse.

\section{Results}

Most patients (83.5\%) were discharged to primary care. Transfer to secondary care was associated with previous in-patient admissions (odds ratio $(\mathrm{OR})=1.92,95 \% \mathrm{Cl} 1.54-2.39$ ) and longer EIP treatment $(\mathrm{OR}=1.04,95 \% \mathrm{Cl} 1.03-1.06)$. Relapse rate was highest shortly after leaving EIP services. Relapse was associated with transfer to secondary care (hazard ratio $(H R)=2.75,95 \% \mathrm{Cl}$ 1.75-4.31), higher deprivation ( $\mathrm{HR}=1.03,95 \% \mathrm{Cl}, 1.01-1.05)$, a substance misuse disorder ( $\mathrm{HR}=1.81,95 \% \mathrm{Cl} 1.01-3.26)$ and a comorbid diagnosis of a personality disorder ( $\mathrm{HR}=2.96,95 \%$ Cl 1.39-6.29)

\section{Conclusions}

Most patients treated by the EIP service in Oxfordshire did not receive ongoing mental healthcare from secondary mental health services. We identified high deprivation and those with substance misuse problems or personality disorders as EIP populations with a high risk of relapse.

\section{Declaration of interest}

None.

\section{Keywords}

Psychosis; early intervention in psychosis; community mental health teams.

\section{Copyright and usage}

(C) The Royal College of Psychiatrists 2018. This is an Open Access article, distributed under the terms of the Creative Commons Attribution-NonCommercial-NoDerivatives licence (http://creativecommons.org/licenses/by-nc-nd/4.0/), which permits noncommercial re-use, distribution, and reproduction in any medium, provided the original work is unaltered and is properly cited. The written permission of Cambridge University Press must be obtained for commercial re-use or in order to create a derivative work.
Early intervention in psychosis (EIP) services are now the dominant service model for treating those with first-episode psychosis (FEP) in many countries including the UK, Australia and Denmark. They are community services that provide pharmacological and psychological treatments, patient and family education and social support, education and employment support, and physical health checks while proactively engaging patients and their families. EIP services are offered for up to 3 years after which patients are either discharged to their general practitioner or transferred to adult secondary mental health services.

Three randomised controlled trials and a number of observational and quasi-experimental studies have shown better outcomes for those treated by EIP services in comparison with usual care, including: fewer positive symptoms, fewer days in hospital, better engagement and adherence, better quality of life, lower mortality and better cost-effectiveness. ${ }^{1-5}$ However, follow-up studies of two trials have found that the beneficial effects of EIP services are not sustained after patients had been discharged from treatment. ${ }^{6-8}$ This lack of effect is not altered by increasing the duration that EIP services are offered, ${ }^{9,10}$ an oft-proposed solution. The longterm course of psychotic illness following FEP, however, is highly variable $^{11}$ and therefore offering the same treatment package to all patients seen by EIP services may not be the most efficient use of resources, and may have diluted the treatment effect seen in follow-up studies. An alternative solution is the early identification of those who are likely to have poorer outcomes, and offering a more tailored approach to their treatment. There is little to guide clinicians on who these individuals may be.

Here we used electronic health record (EHR) data to investigate (a) discharge destinations and predictors of discharge destination, and (b) predictors of relapse in patients discharged from EIP services.

\section{Method}

\section{Setting, participants and data collection}

We conducted a retrospective clinical register cohort study of all patients who had been accepted on to the case-load of two early intervention teams in Oxford and Buckinghamshire, England, between 12 January 2006 (the first EHR documented instance of early intervention in Oxford Health NHS Foundation Trust) and 7 March 2017. Oxfordshire and Buckinghamshire have a combined population of approximately 1.2 million, with a mix of urban and rural settlements. Deprivation is lower than the national average in both regions; however, there are pockets of very high deprivation (among the 20\% most deprived in England) in urban areas such as Oxford city. Mental healthcare for both regions is provided by Oxford Health NHS Foundation Trust.

Mental health data from EHRs were extracted and anonymised by Oxford Health's information management and technology team before being sent to the research team. Follow-up data were 
censored on the 7 March 2017. The data extraction formed part of a service evaluation of the Oxford and Buckinghamshire EIP services and therefore ethics approval was not required.

To be included participants had to be between the ages of 14 and 35. Participants were excluded for the following reasons: if they were still open to the EIP case-load; if they had moved out of the area at any point during EIP treatment or during follow-up; if their only contact with the EIP team was to receive an eligibility assessment; or if they were given a diagnosis of an at-risk mental state.

\section{Measures}

We had two primary outcomes, discharge destination and relapse. Discharge destination was recorded as the type of service that was responsible for the mental healthcare of the patient following their discharge from the EIP service. Destinations were coded into three categories: primary care, adult mental health team (AMHT), and in-patient hospital (those who were discharged from EIP care during an in-patient admission). When conducting the analysis we recoded discharge destination into a dichotomous variable (primary care or specialist mental healthcare) because of the small number of events of transfer to in-patient hospitals (with primary care coded as zero and specialist mental healthcare coded as one). Relapse was defined as any in-patient hospital stay or a referral to a crisis or home treatment team.

We collected information on age at referral to the EIP service, gender and ethnicity (categorised into White, Black, Asian, mixed and other ethnicity). We recorded all International Classification of Diseases (ICD) diagnoses. ${ }^{12}$ We classified primary diagnosis into non-affective psychoses (F20-F24, F26-F29), affective psychoses (F25, F30.2, F31.2, F32.3, F33.3), mood and anxiety disorders (F30-F48, excluding F31.2, F32.3, F33.3), personality disorders (F60-F69) and all other diagnoses. The participant's most recent primary diagnosis on their EHR was recorded as their primary diagnosis. We also collected evidence of substance misuse by recording any instance of a secondary diagnosis of substance misuse disorder.

To estimate social deprivation we used the participants' home address at the time they were discharged from EIP services to calculate neighbourhood-level Index of Multiple Deprivation 2015 (IMD) scores. ${ }^{13}$ The IMD, using data from the national census, combines seven domains (income deprivation; employment deprivation, education skill and training development, health deprivation and disability, crime, barriers to housing and services, and living environmental deprivation) to give an overall deprivation score for 32844 distinct geographical areas in England. Higher scores represent higher deprivation.

We also collected data on mental health service use, including duration of the service and year of referral. If a patient was discharged to primary care and no more entries were made on their secondary care notes, we assumed that they had not received any further secondary mental healthcare unless their postcode had been updated to indicate that they had changed to an address outside of Oxford Health's boundaries, in which case we excluded them for moving out of area.

\section{Statistical analysis}

We calculated descriptive statistics for all demographic and clinical variables. We determined changes to who provided mental healthcare following discharge from EIP services by calculating proportions of the sample discharged to each discharge destination. To account for differences in the length of follow-up in the cohort, we also looked at service provision in a subgroup of participants who had been discharged for 2 years or more.

To investigate differences in discharge destination we examined associations between demographic and clinical variables and discharge destination (primary care versus either AMHT or inpatient care) using a logistic regression, reported as odds ratios (ORs) with 95\% CIs. ORs greater than one indicate a stronger propensity for being referred to AMHT or in-patient care over primary care. We adjusted for age, gender, ethnicity, IMD score, primary diagnosis, number of previous in-patient admissions, duration of EIP treatment and for a diagnosis of substance misuse.

To examine time to relapse following discharge from EIP services we plotted Kaplan-Meier survival estimates comparing those discharged to primary care versus those discharged to specialist mental healthcare. To test for predictors of relapse we conducted a multivariable Cox proportional hazards regression analysis and included age, gender, ethnicity, IMD score, primary diagnosis, number of previous in-patient admissions, duration of EIP, discharge destination and a diagnosis of substance misuse as explanatory variables. We report these as hazard ratios (HRs) with 95\% CIs. We tested the assumptions of proportional hazards by plotting Schoenfield residuals. We managed all data and conducted the statistical analyses using R version 3.4.1 or SPSS version 22 .

We used the multiple imputations procedure in SPSS to impute any missing data. SPSS uses the Markov chain Monte Carlo algorithm for multiple imputations and we included all predictor variables in the imputation model. We produced 36 imputed data-sets and pooled estimates, performing the main analyses with the pooled estimates. ${ }^{14}$

\section{Sensitivity analyses}

We conducted three further sets of sensitivity analyses to test a priori hypotheses. In our first sensitivity analysis we examined predictors of discharge destination and relapse excluding those who were discharged from EIP services while in-patients. Many patients in this subgroup had specific and ongoing intensive care needs, such as being on forensic or psychiatric intensive care unit wards, or severe comorbidity such as an eating disorders, and were transferred to other specialist units. The aim of this sensitivity analysis was to explore whether there was the potential for a few severely ill patients to effect estimates.

Our second sensitivity analysis included a diagnosis of schizophrenia (F20) as a separate diagnostic category in our regression and survival models, to examine whether those with a diagnosis of schizophrenia had different outcomes to other non-affective psychoses. Our third analyses redefined our relapse criteria to investigate predictors of psychiatric in-patient readmission only rather than both admission and crisis and home treatment team referral.

\section{Results}

\section{Clinical and demographic characteristics}

There were 1233 patients accepted on to an EIP case-load who had an EHR between 12 January 2006 and 7 March 2017. There were 532 ineligible participants: $358(29.0 \%)$ were still on EIP caseloads; 117 (9.5\%) had moved out of area, $16(1.3 \%)$ were not aged between 14 and 35 at their first referral to EIP services; 34 (2.8\%) were open to an EIP case-load but only received an assessment; and $7(0.6 \%)$ had an at-risk mental state diagnosis. The final number of eligible cases was 701 .

Table 1 presents the demographics of the sample. The mean age at referral to EIP was 22.25 years (s.d. = 5.17), with a range of $14-35$. One-third were female ( $n=244,34.8 \%)$, and almost two-thirds were recorded as having White ethnicity $(n=442,76.6 \%)$. The median duration of EIP was 602.00 days (interquartile (IQR) $=308.53-$ 1023.07), with $78.2 \%$ of patients having less than 3 years of EIP treatment. The median duration for participants referred prior to 
Table 1 Age, gender, ethnicity and Index of Multiple Deprivation (IMD) decile for patients discharged from early intervention in psychosis services in Oxford and Buckinghamshire between 2006 and $2017(n=701)$

\begin{tabular}{|c|c|c|}
\hline & & $\begin{array}{l}\text { Missing, } \\
n(\%)\end{array}$ \\
\hline Age, mean (s.d.) & $22.25(5.17)$ & $0(0)$ \\
\hline Gender, female: $n$ (\%) & $244(34.8)$ & $0(0)$ \\
\hline Ethnicity, $n$ (\%) & & $124(17.7)$ \\
\hline White & $442(76.6)$ & \\
\hline Black & $26(4.5)$ & \\
\hline Asian & $66(11.4)$ & \\
\hline Mixed & $36(6.2)$ & \\
\hline Other & $7(1.2)$ & \\
\hline IMD decile, ${ }^{a} n(\%)$ & & $8(1.1)$ \\
\hline $1-3$ & $94(13.6)$ & \\
\hline $4-7$ & $299(43.1)$ & \\
\hline $8-10$ & $300(43.3)$ & \\
\hline $\begin{array}{l}\text { Total early intervention service duration, } \\
\text { days: mean (s.d.) }\end{array}$ & $682.61(454.42)$ & $0(0)$ \\
\hline $\begin{array}{l}\text { Admission prior to early intervention service } \\
\text { discharge, yes: } n(\%)\end{array}$ & $213(30.4)$ & 0 \\
\hline Discharge destination, $n$ (\%) & & $0(0)$ \\
\hline General practitioner & $585(83.5)$ & \\
\hline Adult mental health team & 95 (13.5) & \\
\hline In-patient & $21(3.0)$ & \\
\hline Diagnosis, $n$ (\%) & & $63(9.0)$ \\
\hline Schizophrenia & $132(20.7)$ & \\
\hline Other non-affective psychosis & $235(36.8)$ & \\
\hline Affective psychosis & $86(13.5)$ & \\
\hline Mood and anxiety disorders & $117(18.3)$ & \\
\hline Personality disorders & $31(4.9)$ & \\
\hline Other diagnoses & $37(5.8)$ & \\
\hline
\end{tabular}

7 March 2014, including those still open to the EIP case-load (i.e. all those who were able to accrue 3 years of EIP treatment, $n=533$ ) was 753.50 days ( $\mathrm{IQR}=439.97-1144.50)$, with $71.3 \%$ having less than 3 years of treatment. The non-affective psychoses were the most common diagnostic category at discharge $(n=367,52.4 \%)$, and $213(30.4 \%)$ participants had been admitted to an in-patient hospital prior to, or during, their treatment with the EIP team.

\section{Discharge destination}

Most participants were discharged from the EIP service to primary care $(n=585,83.5 \%)$. By 7 March 2017 (the data collection censor date), 446 (63.6\%) of the 701 had been discharged from EIP services for at least 2 years, of whom $372(83.4 \%)$ had been discharged to their general practitioner. Almost a third of this subgroup $(n=119,31.9 \%)$ had been referred back to secondary mental health services within 2 years of discharge.

The odds of a transfer to secondary care significantly increased as the number of in-patient admissions during EIP treatment increased $(\mathrm{OR}=1.92,95 \% \mathrm{CI} 1.54-2.39)$ and as the duration (in months) of EIP treatment increased (OR $=1.04$, 95\% CI $1.03-$ 1.06 , Table 2). The odds of being transferred to secondary care were 1.62 times greater for female patients relative to male patients (95\% CI 1.02-2.57, $P=0.039$ ), whereas the odds of being transferred to secondary care were 2.58 times greater in those diagnosed with an 'other' category diagnosis in comparison with a non-affective psychosis diagnosis (95\% CI 1.06-6.29, $P=0.037$ ). In our sensitivity analysis of discharge destination, which excluded those discharged from EIP services while in-patients (i.e. primary care versus AMHT only), being female was no longer associated with significantly greater odds of transfer to secondary care $(\mathrm{OR}=1.50,95 \%$ CI $0.92-2.44, P=0.101$, nor was having an 'other' diagnosis $(\mathrm{OR}=1.96,95 \%$ CI $0.71-5.41, P=0.194)$.
In our sensitivity analysis that included schizophrenia as a separate diagnostic category, a diagnosis of another non-affective psychosis had reduced odds of transfer to secondary care $(\mathrm{OR}=$ $0.24,95 \%$ CI $0.12-0.46$ ) in comparison with a diagnosis of schizophrenia, as did an affective psychosis diagnosis $(\mathrm{OR}=0.44,95 \%$ CI 0.22-0.89).

\section{Relapse}

Patients were followed up for a median of 1041 days from EIP discharge (until the data collection censor date). Figure 1 shows the Kaplan-Meier curves comparing relapse in primary care or specialist mental healthcare (with those discharged from EIP services while they were in-patients excluded). Table 3 presents the results of the Cox proportional hazard model for the predictors of relapse following EIP discharge. Relapse was significantly higher in those with a diagnosis of a personality disorder ( $\mathrm{HR}=2.96,95 \%$ CI 1.39-6.29) in comparison with a diagnosis of non-affective psychosis. Relapse was elevated as the duration (in months) of EIP treatment increased ( $\mathrm{HR}=1.02,95 \%$ CI 1.01-1.04) and in those who were discharged to specialist care in comparison with primary care $(\mathrm{HR}=2.75,95 \%$ CI $1.75-4.31)$. Relapse was also elevated as deprivation scores increased $(\mathrm{HR}=1.03$, 95\% CI 1.01$1.05)$, and in those with a substance misuse disorder $(\mathrm{HR}=1.81$, 95\% CI 1.01-3.26).

In our sensitivity analysis excluding those discharged from EIP services while in-patients, those with a substance misuse disorder no longer had a significantly higher hazard of relapse, although the trend remained ( $\mathrm{HR}=1.86,95 \% \mathrm{CI} 0.99-3.48)$. In our sensitivity analysis that included schizophrenia as a separate diagnostic category, those with a non-affective psychosis diagnosis excluding schizophrenia had decreased relapse $(\mathrm{HR}=0.37,95 \%$ CI 0.18 $0.75)$, whereas those with a personality disorder had elevated relapse $(\mathrm{HR}=2.43,95 \% \mathrm{CI} 1.16-5.11)$. Being of Asian ethnicity in comparison with White ethnicity also conferred a significantly lower HR (HR $=0.38,95 \%$ CI 0.16-0.91).

Finally, in our sensitivity analysis investigating readmission only (instead of relapse of either readmission or referral to a crisis team), the number of prior admissions ( $\mathrm{HR}=1.27,95 \%$ CI $1.03-$ 1.57), a longer duration of EIP ( $\mathrm{HR}=1.02,95 \%$ CI 1.01-1.04), being discharged to specialist secondary care $(\mathrm{HR}=2.52,95 \% \mathrm{CI}$ 1.49-4.23), a diagnosis of personality disorder compared with non-affective psychosis ( $\mathrm{HR}=2.43,95 \%$ CI 1.01-5.83) and a higher deprivation score ( $\mathrm{HR}=1.04,95 \% \mathrm{CI} 1.02-1.07)$ all conferred a higher hazard of relapse.

\section{Discussion}

Our study confirms much of what is intuitive, or which has already been established, in the care of this group of patients, but also presents some new findings that may warrant a new treatment approach for a proportion of patients.

\section{Discharge pathways}

We found that the majority of EIP patients (83.5\%) were discharged to primary care, which is substantially higher than in previous literature. ${ }^{8,15-19}$ Not only were more people being discharged to primary care, they were being discharged earlier: the median duration of EIP care was almost a year less than the 3 -year stipulated treatment. This may reflect a combination of clinical judgement about need for treatment and pressure on case-load sizes. In support of this, those who were treated for longer in EIP services were significantly more likely to be transferred to an adult community mental health team. 
Table 2 The association between diagnosis, admissions, early intervention duration, age, gender, ethnicity and Index of Multiple Deprivation (IMD) score with transfer from early intervention services to specialist secondary care

\begin{tabular}{|c|c|c|c|c|c|c|c|c|c|}
\hline & \multicolumn{3}{|c|}{ Main analysis ${ }^{\mathrm{a}}(n=701)$} & \multicolumn{3}{|c|}{ In-patient at discharge excluded ${ }^{\mathrm{b}}$} & \multicolumn{3}{|c|}{$\begin{array}{c}\text { Schizophrenia as separate } \\
\text { diagnostic categoryc }\end{array}$} \\
\hline & OR & $95 \% \mathrm{Cl}$ & $P$ & OR & $95 \% \mathrm{Cl}$ & $P$ & OR & $95 \% \mathrm{Cl}$ & $P$ \\
\hline \multicolumn{10}{|l|}{ Diagnosis } \\
\hline Schizophrenia & & & & & & & 1 (reference) & & \\
\hline Non-affective psychosis & 1 (reference) & & & 1 (reference) & & & 0.24 & $0.12-0.46$ & 0.001 \\
\hline Affective psychosis & 0.85 & $0.44-1.65$ & 0.628 & 0.72 & $0.34-1.52$ & 0.393 & 0.44 & $0.22-0.89$ & 0.023 \\
\hline Mood and anxiety disorders & 1.05 & $0.54-2.04$ & 0.883 & 1.19 & $0.62-2.32$ & 0.589 & 0.52 & $0.25-1.07$ & 0.077 \\
\hline Personality disorders & 1.59 & $0.60-4.24$ & 0.347 & 1.52 & $0.53-4.36$ & 0.437 & 0.79 & $0.29-2.19$ & 0.653 \\
\hline Other & 2.58 & $1.06-6.29$ & 0.037 & 1.96 & $0.71-5.41$ & 0.194 & 1.13 & $0.43-3.01$ & 0.801 \\
\hline Number of admissions & 1.92 & $1.54-2.39$ & 0.001 & 1.51 & $1.18-1.93$ & 0.001 & 1.88 & $1.51-2.36$ & 0.001 \\
\hline Early intervention duration, months & 1.04 & $1.03-1.06$ & 0.001 & 1.04 & $1.03-1.06$ & 0.001 & 1.03 & $1.01-1.05$ & 0.001 \\
\hline Age at referral & 1.02 & $0.98-1.07$ & 0.302 & 1.04 & $0.99-1.09$ & 0.092 & 1.02 & $0.98-1.07$ & 0.303 \\
\hline Gender, female & 1.62 & $1.02-2.57$ & 0.039 & 1.50 & $0.92-2.44$ & 0.101 & 1.54 & $0.96-2.46$ & 0.072 \\
\hline \multicolumn{10}{|l|}{ Ethnicity } \\
\hline White & 1 (reference) & & & 1 (reference) & & & 1 (reference) & & \\
\hline Black & 1.18 & $0.45-3.12$ & 0.742 & 1.26 & $0.46-3.46$ & 0.658 & 1.20 & $0.45-3.22$ & 0.718 \\
\hline Asian & 0.77 & $0.37-1.65$ & 0.506 & 0.82 & $0.37-1.79$ & 0.613 & 0.66 & $0.31-1.44$ & 0.298 \\
\hline Other & 1.28 & $0.58-2.84$ & 0.542 & 1.42 & $0.62-3.25$ & 0.410 & 1.19 & $0.54-2.68$ & 0.660 \\
\hline IMD score & 1.00 & $0.98-1.03$ & 0.877 & 1.00 & $0.98-1.03$ & 0.989 & 0.99 & $0.98-1.02$ & 0.966 \\
\hline Substance misuse disorder & 1.16 & $0.59-2.29$ & 0.666 & 1.16 & $0.56-2.40$ & 0.697 & 1.10 & $0.54-2.21$ & 0.789 \\
\hline $\begin{array}{l}\text { Results in bold are significant. } \\
\text { a. Primary analysis including all participant } \\
\text { b. Sensitivity analysis excluding those disch } \\
\text { c. Sensitivity analysis with schizophrenia as }\end{array}$ & d by early in & on in psyc & ervi & ile a psychia & atient. & & & & \\
\hline
\end{tabular}

Referrals to EIP services continue to grow and the expansion of many services to also treat those aged 35 and above has added to pressure at service intake. In contrast, there has not been a relative increase in EIP budgets in the UK nor strategies to reduce case-load pressure further along the service pathway. ${ }^{20}$ It appears that, in our sample, those who are perceived to have less severe illness are being discharged earlier, tailoring EIP treatment according to clinical need. Similar strategies have been used in psychiatric in-patient admission decisions following the reduction in the number of inpatient beds. ${ }^{21}$

The results from our sensitivity analyses also indicated that those with a diagnosis of schizophrenia, personality disorders, or who had 'other' comorbid diagnoses (for example eating disorders or autism) were more likely to be transferred to another secondary mental health service rather than primary care. This may be a further example of clinical judgement, where those with diagnoses traditionally viewed as having a higher likelihood of poor outcome being transferred on to further secondary care.

\section{Relapse}

The strongest predictor of relapse in our cohort was a comorbid diagnosis of personality disorder. Those with a diagnosis of personality disorder had elevated relapse even in comparison with those
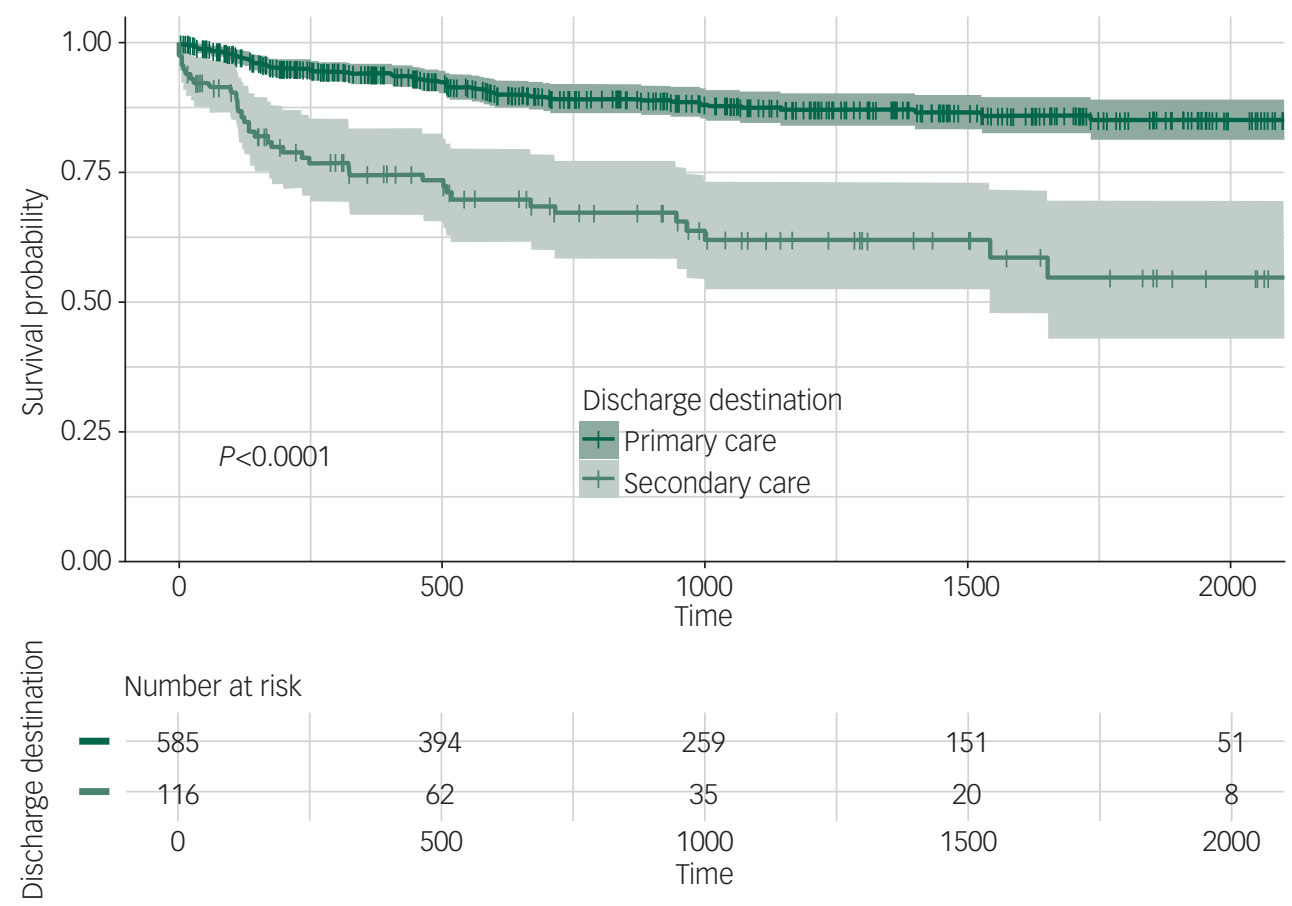

Fig. 1 Kaplan-Meier curve for relapse following discharge from the early intervention team $(n=701)$. 


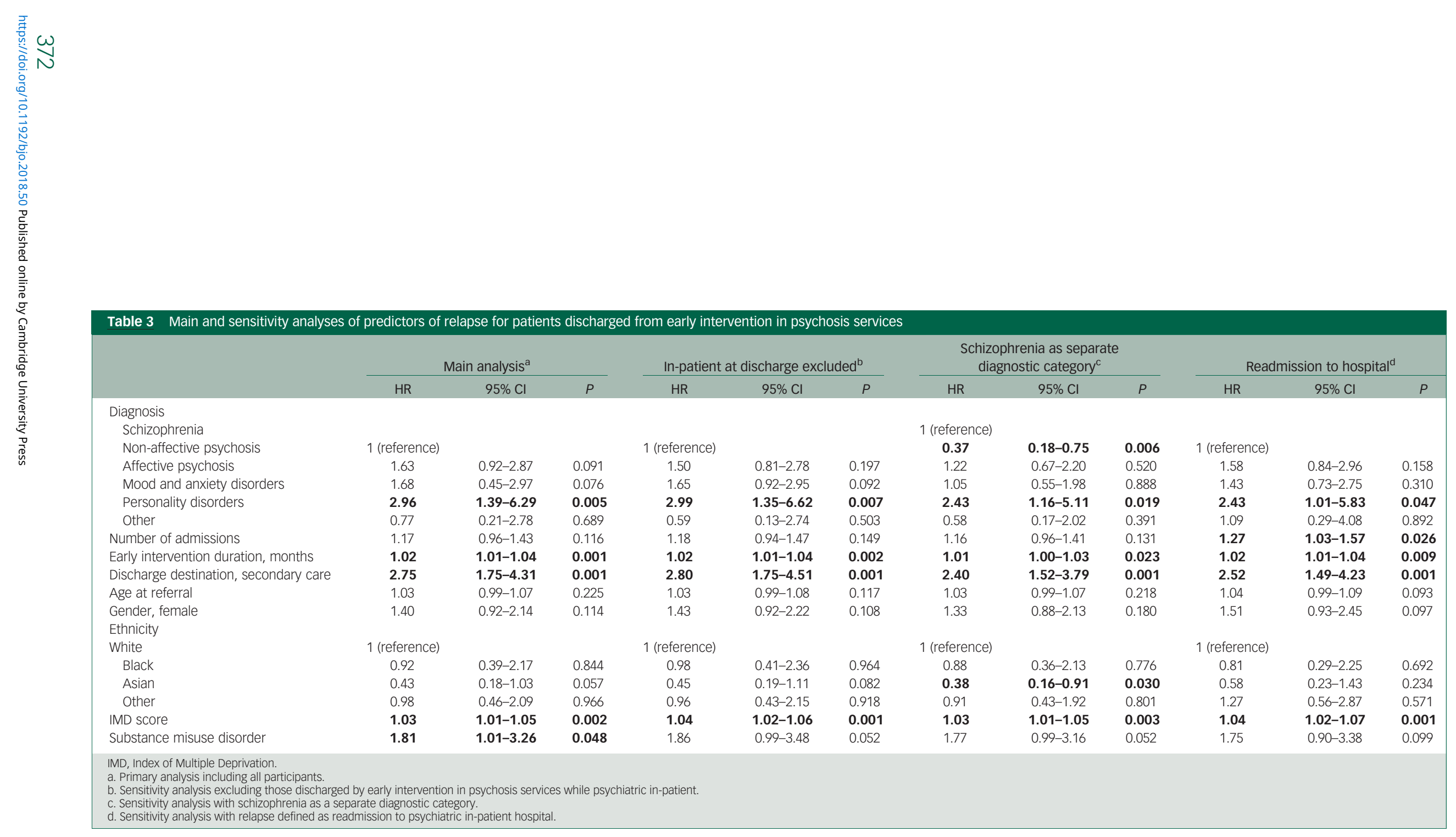


with a diagnosis of schizophrenia. There are also considerable numbers of patients presenting to EIP services with both psychotic and personality disorder psychopathology, ${ }^{22}$ and evidence that people with personality disorder who have psychotic comorbidity may have a poorer clinical course than those who do not. ${ }^{23}$ The question for EIP services is how to best serve the needs of this group of patients. Treatments in EIP services are, understandably, concentrated on reducing psychotic symptoms and the prevention of psychotic disorders, whereas treatments for personality disorder have a different approach. ${ }^{24}$ The provision of personality disorderspecific services also remains highly variable, ${ }^{25}$ whereas pathways into EIP care are more accessible, meaning that most patients with both disorders will be treated in EIP services, rather than a personality disorder service, and the difficulties associated with the personality disorder are not adequately treated. Incorporating appropriate treatment within EIP services, such as dialectical behaviour therapy or social interventions for personality disorder, ${ }^{26}$ may be one approach to improve the outcomes in those with more complex presentations.

We also found that residing in a more deprived area was associated with risk of relapse. There is consistent evidence that suggests higher levels of deprivation are associated with poorer outcomes in mental health, ${ }^{27}$ although some of this may be mediated by genes. ${ }^{28}$ There is remarkably little investigation into social deprivation and outcomes in those with FEP. There is some evidence of neighbourhood effects on psychotic experiences in adolescents, ${ }^{29}$ and increased incidence of psychotic disorders in urban living. ${ }^{30}$ However, deprivation or neighbourhood-level effects have not been found in pathways to care ${ }^{31}$ or disengagement from treatment. ${ }^{32}$ From our results it appears that social deprivation may increase the risk of relapse. What we could not measure is where this increased risk may come from. It may be because of a lack of access to services in areas of higher social deprivation, variation in the use of mental health legislation or a higher likelihood of those with more severe illness residing in socioeconomically deprived neighbourhoods.

Finally, we observed a greater risk of relapse in the months following the transition from EIP services to AMHTs. There could be a number of explanations for this. First, transitions in healthcare are periods of particular risk for patients. Transitions disrupt continuity of care through changes in staff and relationships and changes in treatment. ${ }^{33-35}$ Transitions can also create instability and uncertainty for patients. ${ }^{33,34}$ Patients in EIP services have reported that continuity prior to discharge could be better established to ease the transition, ${ }^{33}$ a theme that is prevalent in transitions across mental healthcare. Managed transitions are currently being trialled in both children and adolescent mental healthcare, ${ }^{36}$ and EIP services may benefit from similar. Second, it may be that a certain intensity of service provision is required to maintain a good outcome. EIP services provide a multidisciplinary, assertive service with a range of pharmacological, psychological and social interventions. They also have specific expertise in treating the early stages of a psychotic illnesses. These resources have traditionally been missing from generic community mental health services. ${ }^{37}$ Third, we cannot rule out that this high rate of relapse may represent a rapid cyclical pattern of relapse for a small group of patients with the most severe illness rather than a relapse that is directly attributable to the change from EIP services to another service.

\section{Limitations}

There are limitations to our study. First, our study only collected data from mental health services. We were unable to link mental health records with primary care data and admissions to other psychiatric or acute hospitals are not included. Oxford Health is the sole provider of adult mental health services as well as child and adolescent mental health services and forensic services for the counties of Oxfordshire and Buckinghamshire, so we have some confidence that all mental health relapses will have been captured. We excluded from our analysis all those who moved out of area during follow-up.

Second, we were unable to measure duration of untreated psychosis (DUP) as it was not recorded uniformly across patients' EHRs. DUP is a recommended measurement in FEP studies despite the conflicting evidence of the role of DUP in relapse. ${ }^{38}$ We were also unable to measure which components of EIP treatment participants received. This would be important in future research to identify which components of EIP may improve longer-term outcomes.

Third, our study only collected data from one region in the UK. Although the catchment region for Oxford Health NHS Foundation Trust includes small pockets of high deprivation, our results are not generalisable to larger urban areas with higher deprivation. Furthermore, our sample had fewer patients with a diagnosis of schizophrenia, which may reflect a FEP sample with less severe illness than in previous literature.

\section{Implications}

This is the largest study investigating discharge and relapse following treatment from EIP services. We found that many patients do not receive the full 3 years of recommended treatment, and most are discharged to primary care following the end of their treatment. Despite this, the majority do not have a severe relapse requiring admission to hospital.

We have identified two particular subgroups that may require further attention. The first is those with a history of prior admissions, from areas of higher deprivation, and who have problems with substance misuse. Identifying this high-risk group who need ongoing assertive community treatment may be a better use of resources than extending EIP services for all FEP presentations and would maintain continuity of care and stability for this vulnerable group. The second are those with a diagnosis of a personality disorder and FEP. Our data suggest that this groups of patients are particularly vulnerable to relapse and readmission, and may benefit from further intervention. Finally, we found that those who required ongoing mental healthcare after treatment from EIP services had a high risk of relapse in the first few months following transfer of care, highlighting the importance of transitions and providing a further focus for improving outcomes.

Stephen Puntis, DPhil, BSc, Research Fellow, Department of Psychiatry, University of Stephen Puntis, DPhil, BSC, Research Fellow, Department of Psychiatry, University of
Oxford, Warneford Hospital, UK; Jason Oke, DPhil, MSc, Senior Statistician, Nuffield Department of Primary Care Health Sciences, University of Oxford, UK; Belinda Lennox BMedSci, BM, BS, DM, FRCPsych, Associate Professor, Department of Psychiatry, University of Oxford, Warneford Hospital, UK

Correspondence: Stephen Puntis, Department of Psychiatry, University of Oxford Warneford Hospital, Oxford OX3 7JX, UK. Email: stephen.puntis@psych.ox.ac.uk

First received 16 Mar 2018, final revision 19 Jul 2018, accepted 3 Mar 2018

\section{Funding}

S.P. is funded by a National Institute for Health Research Post Doctoral Fellowship award (grant number PDF-2017-10-029). This research was funded by the National Institute for Health Research (NIHR) Collaboration for Leadership in Applied Health Research and Care Oxford at Oxford Health NHS Foundation Trust. The views expressed are those of the author(s) and not necessarily those of the NHS, the NIHR or the Department of Health.

\section{References}

1 Craig TK, Garety P, Power P, Rahaman N, Colbert S, Fornells-Ambrojo M, et al. The Lambeth Early Onset (LEO) Team: randomised controlled trial of the effectiveness of specialised care for early psychosis. BMJ 2004; 329: 1067. 
2 Petersen L, Jeppesen P, Thorup A, Abel M-B, Øhlenschlæger J, Christensen Tø, et al. A randomised multicentre trial of integrated versus standard treatment for patients with a first episode of psychotic illness. BMJ 2005; 331: 602.

3 Kane JM, Robinson DG, Schooler NR, Mueser KT, Penn DL, Rosenheck RA, et al. Comprehensive versus usual community care for first-episode psychosis: 2-year outcomes from the NIMH RAISE early treatment program. Am J Psychiatry 2015; 173: 362-72

4 Tsiachristas A, Thomas T, Leal J, Lennox BR. Economic impact of early intervention in psychosis services: results from a longitudinal retrospective controlled study in England. BMJ Open 2016; 6: e012611.

5 Anderson KK, Norman R, MacDougall A, Edwards J, Palaniyappan L, Lau C, et al. Effectiveness of early psychosis intervention: comparison of service users and nonusers in population-based health administrative data. Am J Psychiatry 2018; 175: 443-52.

6 Bertelsen M, Jeppesen P, Petersen L, Thorup A, Øhlenschlæger J, le Quach P, et al. Five-year follow-up of a randomized multicenter trial of intensive early intervention vs standard treatment for patients with a first episode of psychotic illness: the OPUS trial. Arch Gen Psychiatry 2008; 65: 762-71.

7 Secher RG, Hjorthøj CR, Austin SF, Thorup A, Jeppesen P, Mors O, et al. Ten-yea follow-up of the OPUS specialized early intervention trial for patients with a first episode of psychosis. Schizophr Bull 2015; 41: 617-26.

8 Gafoor R, Nitsch D, McCrone P, Craig TK, Garety PA, Power P, et al. Effect of early intervention on 5-year outcome in non-affective psychosis. $\mathrm{Br} \mathrm{J}$ Psychiatry 2010; 196: 372-6.

9 Chang WC, Kwong VWY, Lau ESK, So HC, Wong CSM, Chan GHK, et al. Sustainability of treatment effect of a 3-year early intervention programme for first-episode psychosis. Br J Psychiatry 2017; 211: 37-44.

10 Albert N, Melau M, Jensen H, Emborg C, Jepsen JRM, Fagerlund B, et al. Five years of specialised early intervention versus two years of specialised early intervention followed by three years of standard treatment for patients with a first episode psychosis: randomised, superiority, parallel group trial in Denmark (OPUS II). BMJ 2017; 356: i6681.

11 Morgan C, Lappin J, Heslin M, Donoghue K, Lomas B, Reininghaus U, et al Reappraising the long-term course and outcome of psychotic disorders: the AESOP-10 study. Psychol Med 2014; 44: 2713-26.

12 World Health Organization. The ICD-10 Classification of Mental and Behavioura Disorders: Clinical Descriptions and Diagnostic Guidelines. World Health Organization, 1992.

13 Noble M, McLennan D, Wilkinson $\mathrm{K}$, Whitworth A, Exley S, Barnes $\mathrm{H}$, et al. The English Indices of Deprivation 2007. Communites and Local Government, 2007

14 Bodner TE. What improves with increased missing data imputations? Struct Equ Model 2008; 15: 651-75.

15 Ahmed S, Khan R, Pursglove D, O'Donoghue J, Chakraborty N. Discharges from an early intervention in psychosis service: where do patients stand after 3 years? Early Interv Psychiatry 2015; 9: 48-52.

16 Dodgson G, Ross L, Tiffin P, Mitford E, Brabban A. Outcomes post-discharge from an early intervention in psychosis service. Early Interv Psychiatry 2012; 6: $465-8$.

17 Kam SM, Singh SP, Upthegrove R. What needs to follow early intervention? Predictors of relapse and functional recovery following first-episode psychosis. Early Interv Psychiatry 2015; 9: 279-83.

18 Phillipson A, Akroyd M, Carley J. Audit of discharges from a regional service in the United Kingdom. Early Interv Psychiatry 2014; 8: 91-7.

19 Ahmed S, Peters KZ, Chakraborty N. Discharges from an early intervention in psychosis service: the effect of patient characteristics on discharge destination. Early Interv Psychiatry 2018; March 7 (Epub ahead of print).

20 Rethink. Lost Generation: Why Young People with Psychosis are Being Left Behind, and What Needs to Change. Rethink Mental Illness, 2014 (https:// www.rethink.org/media/973932/LOST\%20GENERATION\%20-\%20Rethink\% 20Mental\%20IIIness\%20report.pdf).
21 Craig TK. Shorter hospitalizations at the expense of quality? Experiences of inpatient psychiatry in the post-institutional era. World Psychiatry 2016; 15: 91-2.

22 Ryan J, Graham A, Nelson B, Yung A. Borderline personality pathology in young people at ultra high risk of developing a psychotic disorder. Early Interv Psychiatry 2017; 11: 208-14.

23 Francey SM, Jovev M, Phassouliotis C, Cotton SM, Chanen AM. Does co-occurring borderline personality disorder influence acute phase treatment for first-episode psychosis? Early Interv Psychiatry 2017; May 18 (Epub ahead of print).

24 Bateman AW, Gunderson J, Mulder R. Treatment of personality disorder. Lancet 2015; 385: 735-43.

25 Dale O, Sethi F, Stanton C, Evans S, Barnicot K, Sedgwick R, et al. Personality disorder services in England: findings from a national survey. BJPsych Bull 2017; 41: 247-53

26 Gleeson JFM, Chanen A, Cotton SM, Pearce T, Newman B, McCutcheon L. Treating co-occurring first-episode psychosis and borderline personality: a pilot randomized controlled trial. Early Interv Psychiatry 2012; 6: 21-9.

27 Murali V, Oyebode F. Poverty, social inequality and mental health. Adv Psychiatr Treat 2004; 10: 216-24.

28 Sariaslan A, Fazel S, D'onofrio B, Långström N, Larsson H, Bergen S, et al. Schizophrenia and subsequent neighborhood deprivation: revisiting the social drift hypothesis using population, twin and molecular genetic data. Trans/ Psychiatry 2016; 6: e796.

29 Solmi F, Colman I, Weeks M, Lewis G, Kirkbride JB. Trajectories of neighborhood cohesion in childhood, and psychotic and depressive symptoms at age 13 and 18 years. J Am Acad Child Adolesc Psychiatry 2017; 56: 570-7.

30 Kirkbride JB, Hameed Y, Ankireddypalli G, Ioannidis K, Crane CM, Nasir M, et al. The epidemiology of first-episode psychosis in early intervention in psychosis services: findings from the social epidemiology of psychoses in East Anglia [SEPEA] study. Am J Psychiatry 2017; 174: 143-53.

31 Anderson KK, Fuhrer R, Schmitz N, Malla AK. Determinants of negative pathways to care and their impact on service disengagement in first-episode psychosis. Soc Psychiatry Psychiatr Epidemiol 2013; 48: 125-36.

32 Doyle R, Turner N, Fanning F, Brennan D, Renwick L, Lawlor E, et al. First-episode psychosis and disengagement from treatment: a systematic review. Psychiatr Serv 2014; 65: 603-11.

33 Lester $\mathrm{H}$, Khan $\mathrm{N}$, Jones $\mathrm{P}$, Marshall M, Fowler D, Amos T, et al. Service users views of moving on from early intervention services for psychosis: a longitudinal qualitative study in primary care. Br J Gen Pract 2012; 62: e183-90.

34 Jones IR, Ahmed N, Catty J, McLaren S, Rose D, Wykes T, et al. Illness careers and continuity of care in mental health services: a qualitative study of service users and carers. Soc Sci Med 2009; 69: 632-9.

35 Sanatinia R, Cowan V, Barnicot K, Zalewska K, Shiers D, Cooper SJ, et al. Loss of relational continuity of care in schizophrenia: associations with patient satisfaction and quality of care. Br J Psychiatry Open 2016; 2: 318-22.

36 Singh SP, Tuomainen H, Girolamo Gd, Maras A, Santosh P, McNicholas F, et al. Protocol for a cohort study of adolescent mental health service users with a nested cluster randomised controlled trial to assess the clinical and cost-effectiveness of managed transition in improving transitions from child to adult mental health services (the MILESTONE study). BMJ Open 2017; 7: e016055.

37 Singh SP, Wright C, Burns T, Joyce E, Barnes TR. Developing early intervention services in the NHS: a survey to guide workforce and training needs. Psychiatrist 2003; 27: 254-8.

38 Alvarez-Jimenez $\mathrm{M}$, Priede $\mathrm{A}$, Hetrick SE, Bendall S, Killackey $\mathrm{E}$, Parker AG, et al. Risk factors for relapse following treatment for first episode psychosis: a systematic review and meta-analysis of longitudinal studies. Schizophr Res 2012; 139: 116-28. 